\title{
TERRITÓRIO E LUGAR: CONSIDERAÇÕES SOBRE O VIVER RIBEIRINHO NO PANTANAL SETENTRIONAL
}

Ingrid Regina da Silva Santos ${ }^{1}$

Maria Geralda de Almeida ${ }^{2}$

Resumo: Objetivamos com o presente artigo esboçar uma aproximação entre os conceitos de território e lugar, com vistas a discutir o modo com o qual o ribeirinho produz o seu espaço. $\mathrm{O}$ olhar reservado às análises é o constituído na Geografia Humanista Cultural. Como metodologia, utilizou-se o levantamento bibliográfico denso, tanto em revistas eletrônicas e livros, observações e entrevistas semiestruturadas. Como resultado, foi possível avaliar que o ser ribeirinho relaciona-se com a morada às margens dos rios e córregos, a pesca tradicional e a economia de subsistência. Seu território foi produzido nas vivências do seu cotidiano e no apego que esses ribeirinhos possuem com o espaço, nas relações estabelecidas que tornam-se o vínculo afetivo com o lugar.

Palavras Chaves: Geografia Cultural. Território. Espaço pantaneiro.

\section{TERRITORY AND PLACE: CONSIDERATIONS ON RIVERINE LIVING IN THE NORTHERN PANTANAL}

Abstract: We achieve with this article to sketch an approximation between the concepts of territory and place, with a view to discussing the way in which the riverine produces its space. The look set aside for analysis is that set up in Humanist Cultural Geography. As methodology, a dense bibliographic survey was used, both in electronic journals and books, observations and semi-structured interviews. As a result, it was possible to evaluate that the riverine being is related to the dwelling on the banks of the rivers and streams, the traditional fishing and the subsistence economy. Their territory was produced in the experiences of theirs daily life and in the attachment that these riverside possess with the space, in the established relations that become the affective bond with the place.

Key words: Cultural Geography. Territory. Pantanal space.

\section{TERRITORIO Y LUGAR: CONSIDERACIONES SOBRE EL VIVIR RIBEREÑO EM EL PANTANAL SENTENTRIONAL}

Resumem: El objetivo de este artículo es hacer una conexión entre los conceptos de territorio, el lugar, con el fin de discutir la manera con el ribereño produce su espacio. La investigación hace uso de la mirada común en la geografía cultural. Como la metodología, se utilizó el levantamiento denso, tanto en revistas y libros electrónicos. Como resultado de ello fue posible evaluar la orilla del río está siendo guiado por la dirección de las orillas de los ríos y

\footnotetext{
1 Programa de Pós-Graduação em Geografia. Instituto de Estudos Sócio-Ambientais. Email: ingridufmt@hotmail.com

${ }^{2}$ Universidade Federal de Goiás. Email: mgdealmeida10@gmail.com
} 
arroyos en la economía de subsistencia y la pesca tradicional. Su territorio fue produzido las vivencias de su vida cotidiana y el apego que los hombres del río tienen con el espacio, es decir, las relaciones establecidas que se transforman en el vínculo emocional con el lugar.

Plalabras Claves: Geografia Cultural. Territorio. Espacio pantaneiro.

\section{Introdução}

A História oficial de Mato Grosso tem seu início no século XVIII, em função do curso d'água, que, posteriormente, foi batizado de Rio Cuiabá. Afluente da bacia do Paraguai éconsiderado importante para o estado por distintos aspectos. Dentre os relevantes, podemos destacar tanto os aspectos biológicos, por ser um dos principais formadores do Pantanal, quanto sociocultural, pois é fonte de significação e identificação dos ribeirinhos e outros grupos (SILVA, 1995; BORGES, 2009).

Deste modo, podemos enunciar que a História do rio, do povo e do estado conflui e corrobora com a constituição do futuro e para o desvelar do presente dos sujeitos deste estudo. Não se sabe ao certo quantas comunidades ribeirinhas estão localizadas às margens do Rio Cuiabá, nem quais deixaram de existir ao longo dos processos espaciais e históricos. Entretanto, é possível afirmar que de sua montante até a sua jusante (pouco mais de $945 \mathrm{~km}$ ) é marcado por uma rica diversidade cultural.

Sobre os sujeitos, homens e mulheres dos rios e ribeiros, vale contextualizar que são frutos da miscigenação entre negros alforriados, bandeirantes e indígenas moradores das margens do Rio Cuiabá. Que sempre viveram/vivem por meio de contato direto com o recurso utilizando esse bem cotidianamente para a pesca, a dessedentação humana e animal, lazer e meio de locomoção (BORGES, 2009).

De modo a avaliar a existência dos sujeitos, objetivamos, por meio do presente artigo, esboçar uma aproximação entre os conceitos de território e lugar, com vistas a discutir o modo pelo qual o ribeirinho dá sentido ao seu espaço. A fim de, conduzir o leitor a compreensão do citado propósito, elegeu-se as seguintes questões: Como os ribeirinhos tradicionais produzem o espaço que habitam? É possível atribuir ao ambiente que faz a composição do Rio Cuiabá a tutela de território das pessoas que ali estão? Como o lugar participa na constituição do território vivido desses homens e mulheres?

No ensejo de responder à problemática levantada, utilizamos como procedimento metodológico o levantamento bibliográfico, entrevistas semiestruturadas e a observação. Na 
primeira investigação identificamos as teses, dissertações e artigos de revistas relacionados a temática abordada e aos sujeitos envolvidos. Na segunda, efetivamos pesquisas de campo. Nela foram feitas observações e entrevistas semiestruturadas com ribeirinhos em diferentes localidades do rio Cuiabá, em Mato Grosso.

Sobre o corpus teórico, a abordagem utilizada é a Geografia Humanista Cultural. No tocante à história do pensamento geográfico, muitos foram os olhares direcionados à compreensão da relação homem e espaço. Das múltiplas feições da citada ciência, o que mais tem se aproximado dessa incumbência são as abordagens de influência humanista, corrente intelectual europeia que surgiu na década de 1960.

Os princípios difundidos pelo mencionado movimento foram um importante aporte na reelaboração do projeto teórico-metodológico geográfico e viabilizou um novo tratamento a subjetividade humana. Ele permitiu que as análises da Geografia fossem além de estudos que quantificavam o relacionamento do homem com a natureza (TUAN, 1995; GOMES, 2011; HOLZER, 1997).

Para Almeida (2009), Geografia de orientação cultural e, para Holzer (1997), a geografia de corrente humanista não deve ser considerada uma nova vertente do pensamento geográfico, mas um enfoque para os estudos espaciais. Kozel (2013) as define como componentes de uma "Geografia Marginal", que se empenha em abordar tudo aquilo que é espacialmente invisibilizado. Isto é, não podem ser apreendidos por um olhar tradicional, como os territórios do desejo, os sentidos da prostituição, os significados dos odores e sabores nas paisagens e nos lugares.

O novo prisma científico, oportunizado à Geografia, é resultado da aproximação dessa ciência com diferentes modos de viver e formas de arte. A literatura, música, gênero e alimentação são apenas alguns dos desafios interpretativos para o geógrafo (CHAVEIRO, 2014). Na mesma linha de consideração, Almeida (2009, p.258) afirma que [...] "o geógrafo é convidado a valorizar as diferenças e a diversidade, procurando explicar, interpretar as realidades concretas, as atividades mentais e as representações que são da imaginação".

Em termos teórico-metodológicos, Almeida (2009), no que se refere à orientação cultural, e Gomes (2011), na humanista, afirmam que, elas são compostas de referências variadas. Não há um aporte que possa ser designado como universal a todos os estudos. Deste modo, é possível aferir pesquisas com enfoques que transitam do método estruturalista ao existencialista. 
Na miscelânea de direcionamentos possíveis nas supracitadas abordagens, é possível identificar pontos de vista que podem dialogar e se contrapor. Para Gomes (2011), o único elemento inaceitável é o empobrecimento oriundo de modelos matemáticos pré-estabelecidos que, por muito tempo,encaixotou o homem.

Em suma, a proposta do que compreendemos como Geografia Humanista Cultural partilha a concepção de que o homem é um ser múltiplo, impossível de ser definido de modo estanque, como um ser acabado. E, deste modo, deve ser "considerado em toda sua complexidade cultural e antropológica" (ALMEIDA, 2008, p. 35).

No que se refere às categorias de análise, trataremos doTerritório e do Lugar.O primeiro está alicerçado em uma perspectiva do mundo vivido. Para isso utilizaremos como referencial as obras de Bonnemaison (2002), Holzer (1997) e Almeida (2008). De forma genérica, para os citados autores, o território existe em diferentes dimensões. Um desses enfoques afirma que ele emerge pelas vivências, igualmente pelas relações estabelecidas por meio dos lugares. No que se refere à categoria lugar, utilizaremos o aporte de Yi Fu Tuan (1995), tomando como base a ideia de enraizamento, da pausa e segurança.

$\mathrm{O}$ artigo está estruturado em três seções. A primeira delas temo propósito de indicar alguns aspectos que corroboraram na constituição do ser ribeirinhos. Na segunda seção, serão expostos os aspectos que figuram o território vivido. Na terceira parte, discutiremos, de modo sucinto, a categoria lugar, e o papel que ele desempenha na constituição da dimensão vivida do território. Por último, abordaremos os lugares e itinerários vividos pelos sujeitos.

\section{Aproximações para se pensar os ribeirinhos}

Os "homens e mulheres que foram ficando" seria uma definição da essência da formação dos sujeitos, a qual trataremos com o presente artigo. Essa afirmação nos ocorre ao tentar identificar o nexo da constituição do que é ser ribeirinho. Quando nos indagamos qual é o histórico dessas pessoas, quais foram os processos do espaço que ocupam. As respostas, nos esclarece que são negros alforriados, bandeirantes e indígenas, esses moradores das margens do Rio Cuiabá (BORGES,2009). São sujeitos que foram ficando nas margens do Rio Cuiabá, e nele aprenderam a trocar, isto é, ser como ele, e ser em função dele, e dele se fazer.

A primeira menção aos ribeirinhos que se tem documentado no estado de Mato Grosso está na verdade, relacionada à existência de indígenas que habitavam essa região, no período 
de 1750. Conforme Silva (1995), Antônio Rolim de Moura foi o primeiro a relatar as choupanas de grupos que lembravam pescadores.

Até o final do século XIX, os ribeirinhos eram aqueles pequenos agricultores, portadores de relativa autonomia, que, entretanto, também estavam ligados, por meio de vínculos trabalhistas, às fazendas, às usinas e aos engenhos de cana de açúcar. A pesca era uma atividade com objetivo de suprir as necessidades energéticas, isto é, o próprio consumo familiar (BORGES, 2009).

Este cenário discorrido por Borges (2000) perdura até aproximadamente a década 1960. Após esse período ocorre uma grande mudança social no local em decorrência do findar dos engenhos e das últimas usinas de açúcar às margens do Rio Cuiabá. Segundo Da Silva (2009), na ocasião, os ribeirinhos carecem de uma fonte substancial de renda e se voltam para a pesca com a finalidade comercial. E essas pessoas passam a ter a citada atividade como principal elemento de sua identidade.

$\mathrm{Na}$ atualidade, pode-se afirmar que o "ser" ribeirinho permeia distintas formas de vivência, e todas elas estão ligadas de forma direta ou indireta ao ambiente em que estão inseridos. Estes homens e mulheres estão envolvidos com a pesca, agricultura, artesanato e gestão de restaurantes (peixarias).

Silva (2011) reflete que o tempo dessas pessoas está associado a lentidão involucrada no ritmo na natureza. É essa que determina as razões pelas quais se planta, se colhe e se escolhem os espaços de uso. Diz ainda que, o modo de vida pode não ser compatível com as leis que gerenciam o cotidiano dos demais grupos culturais.

Na mesma linha de pensamento, para Borges (2009) essa proximidade é tão forte, que permite afirmar que a sua lógica espacial e cultural é orientada pelos fenômenos naturais. Alguns autores chegam a sugerir a interpretação de que a relação entre os ribeirinhos e a natureza é profunda ao ponto de serem considerados simbióticos (FRAXE, 2004; FERREIRA, 2010).

As práticas culturais são um importante componente para a produção das espacialidades. São elas que mediam a relação do homem com a natureza e ajudam a construir o mundo (CLAVAL, 2007). E é por ela que os vínculos territoriais são estabelecidos, "Há assim uma herança cultural que permeia a relação com o território" (ALMEIDA, 2008, P.317). A tradução da cultura para o espaço passa pelo território (BONNEMAISON,2002). 
Com base neste pressuposto, apresentaremos alguns elementos importantes do ser ribeirinho que corroboram com a sua relação territorial.

\section{O território vivido no ambiente do grande pântano}

A categoria território surge na etologia como uma alternativa para o estabelecimento das espacialidades, e fronteiras com base na conduta conflituosa de animais e organismos (HOLZER, 2003). Como argumenta o autor, esse contexto foi um dos fatores fundamentais para que o termo estivesse sempre associado ao controle e à defesa do espaço.

Foi nas Ciências Sociais que esta categoria adquiriu novo arcabouço teórico. Como, por exemplo, na Geografia, a princípio, o território era utilizado para formalizar a área de atuação do poder dos Estado-Nações. Discutia-se apenas o que dizia respeito às fronteiras que separavam uma nação das outras. Valorizava-se o sentido de patriotismo, pressupondo homogeneidade aos povos.

Na contemporaneidade discute-se também a sua emergência em decorrência de outros modos de se relacionar com o espaço. Neste sentido o território é, também, compreendido como "objeto de operações simbólicas e é nele que os sujeitos projetam o seu modo de vida" (ALMEIDA, 2008, p. 218).

Como orienta Haesbaert (2010) é possível conjecturar que a Geografia possui pelo menos três abordagens para a categoria território, sendo elas jurídico-político, culturalista e econômica. Das três, a política e a econômica são as mais difundidas, com o maior número de pesquisas na atualidade. A de orientação cultural é a de menor número de adeptos assumidos, o que não inviabilizou que elementos da citada natureza fossem contemplados nas análises.

Em virtude do modo com o qual os ribeirinhos se organizam espacialmente, a abordagem utilizada é a culturalista. Essa, para De Paula (2011), é constituída a partir da vivência dos sujeitos e está teoricamente sistematizada por autores da Geografia HumanistaCultural.

Quando se tratam de grupos culturais tradicionais, tal como os ribeirinhos, não é possível pensar um território apenas em seu sentido objetivo. Nessa perspectiva, Little (2002) contribui ao afirmar que em um cenário no qual há dinâmicas de apropriação do espaço de diferentes grupos sociais é conjectural que elementos como os hábitos, valores e costumes reverberem na constituição territorial. 
Cada povo, ao seu modo de se relacionar com o ambiente, também configuram territorialidades. Esses movimentos precisam ser explorados a fim de contribuir para analisar a sociedade de modo mais particular. Ponderar uma abordagem em que seja considerado o território sob a perspectiva da vivência é essencial neste contexto.

Dentre os autores da Geografia, Bonnemaison (2002) foi um dos que alvidraram a correlação entre o vivido e a conformação de territorial. Para o geógrafo, a citada categoria, juntamente com a etnia, deveriam ser base para abordagem cultural. A etnia por ser fundada em um "espaço-território" e o território por não existir no mundo um grupo que não tenha necessidade cultural ou física de uma parcela de espaço.

Além disso, é importante destacar que a reflexão do aludido autor se refere a realidade de sociedades tradicionais insulares. Como examina o mesmo, a principal dificuldade é "saber se o tipo de abordagem que fui levado a adotar para compreender essas sociedades pode ou não acrescentar alguma coisa para os geógrafos que trabalham com sociedades e ambientes físicos diferentes" (BONNEMAISON, 2002, p.83).

Em nossa concepção, o itinerário proposto pelo supracitado autor, em seu artigo "A viagem em torno do território", corrobora com a compreensão de outras realidades, se refletirmos a partir da importância que os lugares possuem em sua constituição. Isso posto, pode-se pensar naquele que nasce da espontaneidade do cotidiano.

Ao ponderarmos o contexto dos ribeirinhos, abstraindo-se da perspectiva instrumental, que são as fronteiras municipais, o espaço determinado como urbano e rural, ou até mesmo em bairros. O território desses homens e mulheres será estabelecido tanto pelos seus lugares, como por seus itinerários.

Enfim, fica claro para Bonnemaison (2002), que os homens são protagonistas de todo o processo de produção do seu território. As dinâmicas que formulam o território vivido não são suplantadas pelo poder do Estado ou qualquer outra forma de produção cartesiana, mas, sim, essas emergem da relação de enraizamento que os grupos mantêm com os itinerários e os lugares.

No caso dos ribeirinhos, pescadores tradicionais, é importante frisar que o território foi concebido em virtude de processos históricos, dos saberes, vivências e afetividade e relação com o ambiente. No que se referem às proposições políticas propriamente ditas, elas se encarregaram de reformular as fronteiras do território vivido, igualmente alteram territorialidades. 
Em nossa concepção, a espacialidade de assentamento dessas pessoas até certo ponto se constituiu naquilo que o Bonnemaison (2002) define como "território de errância". Esta denominação é utilizada geralmente para tratar do contexto de nômades e dos povos caçadores-coletores, territórios nos quais a noção de fronteira é nula.

Assim, há povos em que a noção de fronteira é praticamente inexistente, sem que isso signifique que eles não tenham território. Os nômades, ou alguns povos caçadores coletores, por exemplo, tem uma área de percurso com contornos fluidos e que, ainda que pouca frequência pode eventualmente ser partilhada com outros; mas eles se ligam a um determinado número de "pontos fortes" fixos e itinerários reconhecidos que determinam os “territórios errância" (BONNEMAISON, 2002, p.100).

A inexistência de fronteiras dos ribeirinhos pescadores tradicionais, ainda hoje, pode ser percebida em algumas práticas cotidianas. A pesca é um exemplo, pois os pontos são espaçados por todo o ambiente, nos rios entre os biomas Pantanal e Cerrado, independem das fronteiras estaduais e municipais.

Outro elemento relevante e característico do território vivido, conforme Bonemaison (2002), e com correspondência em Yi-Fu Tuan como essencial do lugar, é a sensação de segurança que causa em seus ocupantes. Na vivência dos ribeirinhos, apesar de habitarem um ambiente considerado "selvagem", em termos naturais, esse não é causador de medos e receios. Na concepção dos sujeitos, estar na comunidade, no rio ou nas baias significa estar distante da violência a que estão expostas as pessoas que moram no território urbano.

\section{Os lugares do viver ribeirinho}

$\mathrm{Na}$ Geografia, ao longo de sua trajetória, houve reinvenções no caráter histórico e filosófico do lugar. Como, por exemplo, Vital de La Blache, citado por Helph (1976) e Holzer (1999, p. 1), que afirma ser o campo da geografia "os lugares não os homens". Até mesmo Hartshorne (1959), que, em uma perspectiva similar, nos dá a entender que se deve cumprir a diferenciação do que ocorre nos lugares (apud HOLZER, 1999, p.1).

Ao transcender o papel de mera localização em um ponto do espaço, como era abordado no passado, o lugar passou a ser avaliado por perspectivas diferentes. Quando objeto dos geógrafos humanistas, a categoria corroborou a renovação de um projeto científico. 
Conforme a leitura de Oliveira (2014), neste momento, o lugar passa a significar a essência da ciência geográfica.

O lugar tem apresentado nos últimos anos crescente valorização. Ele tem sido utilizado como fundamento em estudos de profissionais que pertencem a diferentes áreas. Dentre os atuantes é possível citar geógrafos, ambientalistas, antropólogos e historiadores, arquitetos, paisagistas. Todos com o olhar que pode variar entre crítico, fenomenológico e existencial (RELPH,2014).

No campo da ciência geográfica, citaremos algumas abordagens como, por exemplo, a dimensão relacional, como proposto por Carlos (2007), ou fundante do ser, no que se refere à abordagem de Relph (1976), e a perspectiva da afetividade, como já mencionado em Tuan (1980), para discutir o lugar, para compreender o modo e o porquê os grupos, apesar dos impeditivos e das complexidades presentes no meio, se enraízam ou não a uma parcela do espaço.

No cenário de crescimento das produções que trazem o lugar em seus questionamentos, Relph (2014) conclui que dois panoramas são importantes. Primeiro a falta de respostas ocasionada pelo pensamento cartesiano. O segundo é a necessidade de se conservar as histórias dos espaços, que sofriam/sofrem com a modernização. Esses aspectos foram fundamentais para a valorização do lugar enquanto categoria de estudo.

Com a intenção de entender e reconhecer o território vivido dos ribeirinhos tomaremos como percurso o exame do lugar. Isto posto, procuraremos nos ater a identificação dos lugares e itinerários da vida ribeirinha. $\mathrm{O}$ conceito nesse sentido assume o seu potencial de enraizamento, igualmente de segurança, como proposto por Tuan (1980).

Na opinião de Bonnemaison (2002), os lugares que conferem o sentido do território vivido são distintos no que se referem à hierarquização. Isto é, eles possuem valores descoincidentes. No entanto, todos são significativos no que concerne à existência do grupo.

No enraizamento, o sentimento de estabilidade caracteriza e dá sentido ao território vivido. No tocante à constata importância do lugar para a conformação territorial o definimos sob aporte do vivido. Para isso nos apoiamos na produção teórico de Tuan (1983), que via de regra, em nossa análise é a mais apropriada por dialogar com o que é proposto por Bonnemeison. 
A relação entre o território vivido e a concepção de lugar está no que De Paula (2009) estabelece como a formulação de um "mundo" pessoal ou até mesmo intersubjetivo. Como já mencionado, Bonnemaison assume o território vivido como um arquipélago de lugares.

Aos passos da leitura de Tuan (1980), é possível ponderar que, ao interpretar as vertentes do lugar, o pesquisador transita em diferentes fisionomias da natureza humana. Para o supracitado autor, o lugar pode despertar no indivíduo tanto a afeição quanto a repulsa. Sentimentos que o mesmo define como topofilia.

O enraizamento, lugar ou topofilia só existe quando uma parcela do espaço passa a ter valor para os grupos. Não importa a escala, é sentido de pertencimento que leva o indivíduo a se sentir em estabilidade.

Mas o que é sentir-se em estabilidade? As características descritas no Dicionário Houaiss (2014) nos remetem a sensação de segurança, aquilo que é fixo. A segurança conforme Tuan (1980) é encaminhada para a relativização, sob o ponto de vista das percepções, das atitudes e dos valores envolvidos.

Apesar de sermos animais comuns, as nossas percepções são diferenciadas. É essa variação de percepção e o vínculo adquirido com o lugar que nos faz sentir pertencente ao que pode ser topofóbico como um bairro violento, às casas ameaçadas na encosta, ou a ambientes naturais altamente hostis.

Em síntese, os indivíduos que permanecem nesses espaços austero normalmente, são possuídos pela sensação de contentamento por conseguirem superar as adversidades. A familiaridade e a consciência do passado são sentimentos que trazem à tona as formas de enraizamento de um grupo ao espaço, o que é possível compreender como um lugar.

Presente no cotidiano dos ribeirinhos identificou-se cinco lugares significativos para a constituição de seu território vivido e percebido: as comunidades, o rio, as baias de Sinhá Mariana e Chacororé, e as praias.

As comunidades são os locais onde está estabelecido o lar dos ribeirinhos. Geralmente, elas são compostas por residências, organizadas lado a lado, com a frente voltada para o Rio Cuiabá. As casas possuem duas estruturas básicas: alvenaria ou barro, elas são pequenas, com aproximadamente 15 e 20 metros quadrados, compostas por, no máximo, quatro cômodos (Fig. 1). 

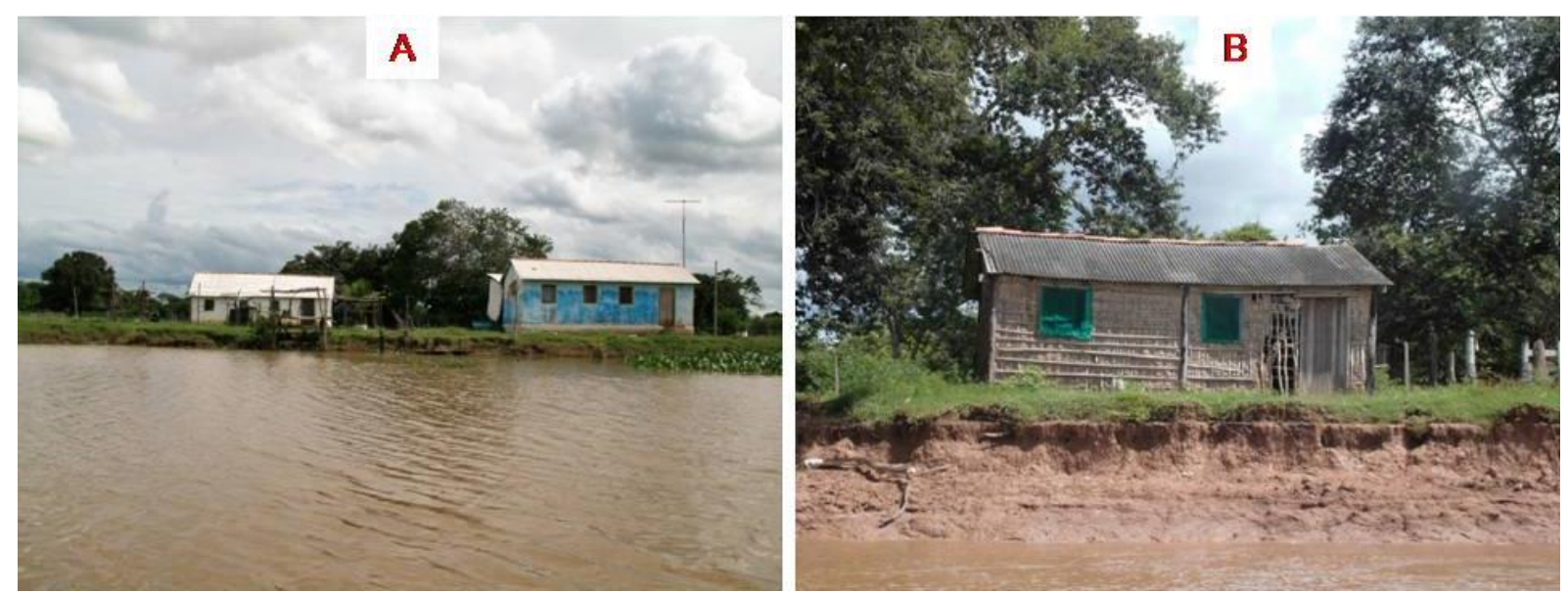

Figura 1 - Residências ribeirinhas na margem do Rio Cuiabá: A - Casa de Alvenaria; B Casa de Pau a pique (madeira e barro), município Barão de Melgaço - MT.

Todas as casas possuem quintais, tanto da frente quanto o do fundo. Sobre a relevância desse espaço para as comunidades rurais, Almeida (2016) elabora uma importante reflexão sobre quintais em seu artigo "Comunidades tradicionais quilombolas do nordeste de Goiás: quintais como expressões territoriais". Embora a experiência divulgada por esta autora seja com uma comunidade quilombola, essa proporciona ao leitor o entendimento da localidade como uma possibilidade à Geografia.

O quintal sob uma dimensão geográfica tornou possível a identificação da importância dessa localidade para a produção e reprodução cultural dos sujeitos ribeirinhos. Eles são utilizados para o cultivo, desenvolvimento das atividades domesticas, criação de pequenos animais, lazer, socialização familiar e confecção de artesanato.

No tocante ao cultivo, pode-se dizer que esse é direcionado para o consumo familiar, gêneros como ervas medicinais, hortaliças legumes, frutas e poucas verduras. Mandioca, abóbora, milho, couve, cana-de-açúcar, banana, acerola, manga, jabuticaba, limão, caju, mamão, laranja representam a base alimentar disponível em grande parte das residências investigadas.

Nas comunidades, há a presença de uma escola municipal, na qual são alfabetizados crianças e adultos. Além disso, é importante destacar que os professores geralmente são os moradores com o maior nível de instrução. A dificuldade de acesso às comunidades é o argumento utilizado para justificar a ausência de profissionais com melhor qualificação nas salas de aula. 
Há também os ranchos onde geralmente ocorrem as celebrações, festas populares e de santos. Eles possuem estrutura de madeira e telhado de palha sem calçamento (Fig. 2). No cotidiano, o rancho serve de abrigo para os animais domésticos, área de lazer das crianças e socialização dos adultos. A sua manutenção é feita uma vez ao ano, nos dias que precedem as comemorações.

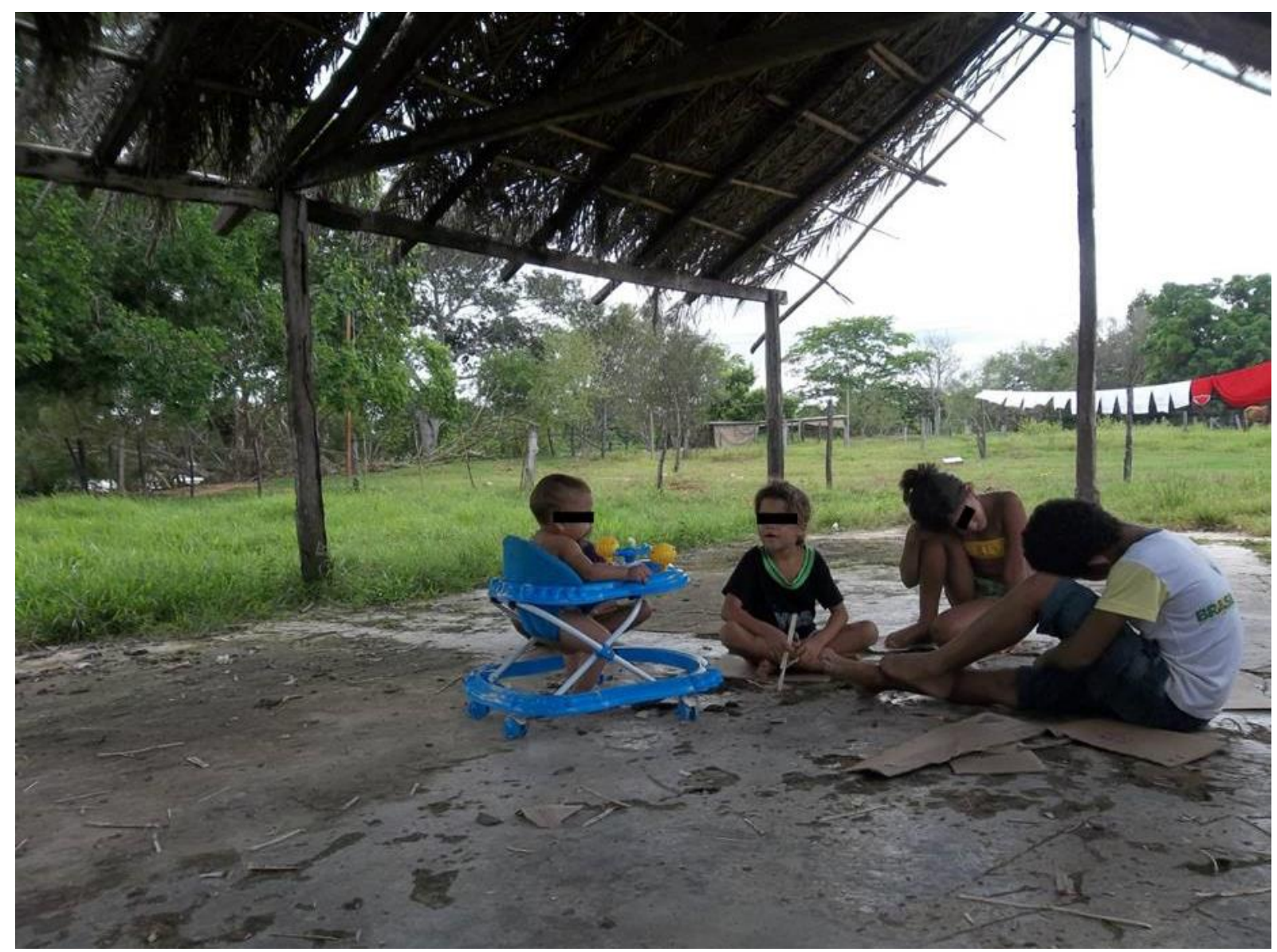

Figura 2: Rancho, sem manutenção e usado para brincadeiras das crianças da comunidade.

Cada comunidade distingue-se por sua historicidade. Na maioria das vezes, elas são originárias da emissão dos documentos de sesmarias, outras da transferência de terra por herança. De modo geral, os seus membros possuem um grau de parentesco. Em termos hierárquicos, ela é considerada o lugar mais importante para os ribeirinhos.

É também na comunidade onde o sentimento de segurança emerge com mais intensidade. Com base na fala dos sujeitos, é nessa localidade que estes homens e mulheres estão resguardados dos perigos habituais. É para ela que o desejo de retornar aponta quando estão distantes. 
Esse apego histórico e a permanência nas comunidades, apesar de as dificuldades, como as enchentes, falta de acesso a serviços básicos, marcam a relação conflituosa dos ribeirinhos com o Pantanal. O vínculo característico do lugar geográfico, conforme Tuan (1980) é também, criado da necessidade, tal como eles que possuem de se manterem e, se possível, em ganhar a vida com a pesca.

Também, como lugar para os ribeirinhos, são os rios. Foi atravessando esse afluente do Paraguai que os forasteiros adentraram em terras que hoje denominamos de estado de Mato Grosso. É por meio desse recurso que os homens e mulheres podem estabelecer a sua existência. Em função da cheia e vazante de suas águas é que o ambiente flui. E o Rio Cuiabá se realiza como a principal fonte de sustento pela pesca, de grande parte dos ribeirinhos (Fig. 3)
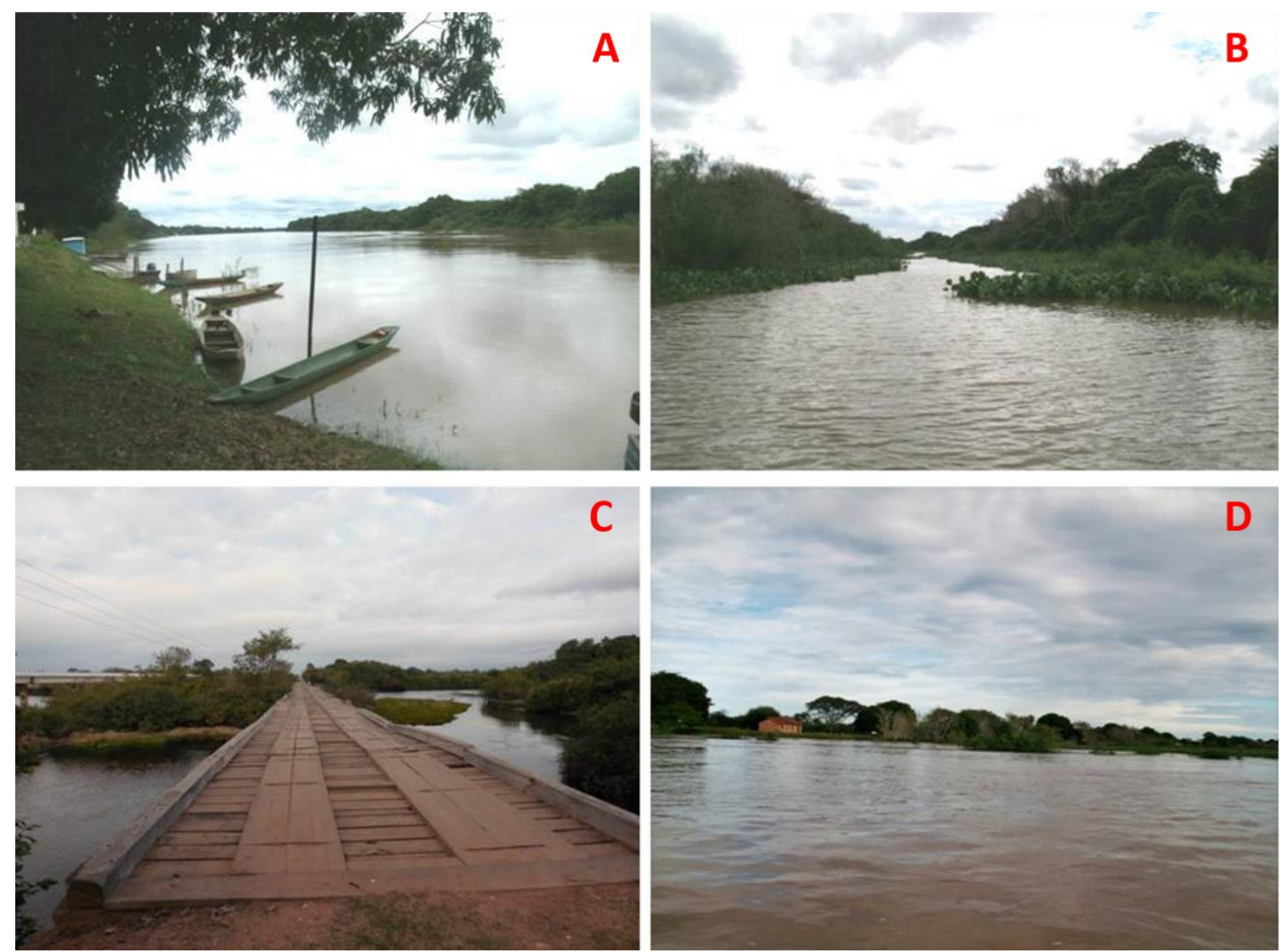

Figura 3: Visualização de alguns rios utilizados pelos ribeirinhos em seu cotidiano. A) Rio Cuiabá; B) Corixo Grande; C) Rio Mutum e, D) Rio Cuiabá. 
A pesca, como produtora de espacialidade, segue um padrão específico de tempo, deslocamento e necessidade. Isto é, ela pode ser caracterizada em tempos longos e curtos. A primeira quando as pescarias duram meses e possuem como objetivo a comercialização. Os pescadores nesta modalidade se dirigem até a fronteira com Mato Grosso do Sul em barco alugado pelas empresas da rede de restaurantes.

De tempo curto, quando ela acontece diariamente com o objetivo de suprir as necessidades diárias de alimentação, comercio local ou para os eventos festivos (Fig. 4). Os pescadores nesta categoria se dirigem, no mais distante para eles, nas proximidades das Baias de Chacororé e Sinhá Mariana.
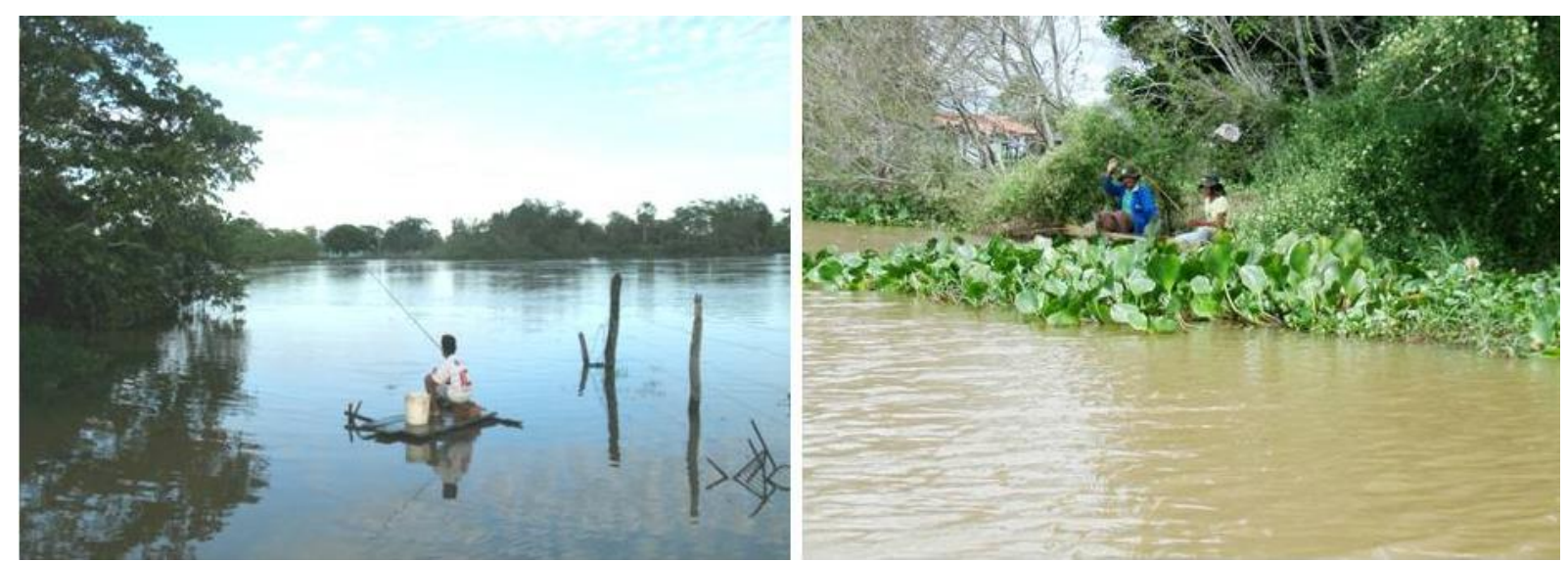

Figura 4: A prática da pesca ribeirinha no Pantanal.

O que define a espacialidade da atividade pesqueira, tanto as de tempos longos como as de tempos curtos, são os saberes tradicionais. Para Almeida (2006, p.11) [...] "O chamado 'tradicional'[...] além de ser do tempo presente, o 'tradicional' é, portanto, social e politicamente construído".Os saberes são transmitidos e herdados. O citado conhecimento é adquirido com a experiência, constituída na vivência do cotidiano, na relação homem com o ambiente natural.

Ademais, o rio é a principal via nos dias em que as águas do Pantanal estão fluindo com intensidade para todos os lados. Contudo, paradoxalmente, e uma parcela das terras que o margeia fique submersa e seus homens e mulheres em relativo isolamento.

Além disso, o rio funciona como uma alternativa de lazer no momento em que as praias começam a emergir, no período da vazante e seca. Isso entre os meses de maio e setembro. Nelas, é possível banhar-se no rio. As praias também são bastante procuradas por 
visitantes de localidades distintas. Esses se reúnem para beber, ouvir música e comer peixe frito (Fig. 5).

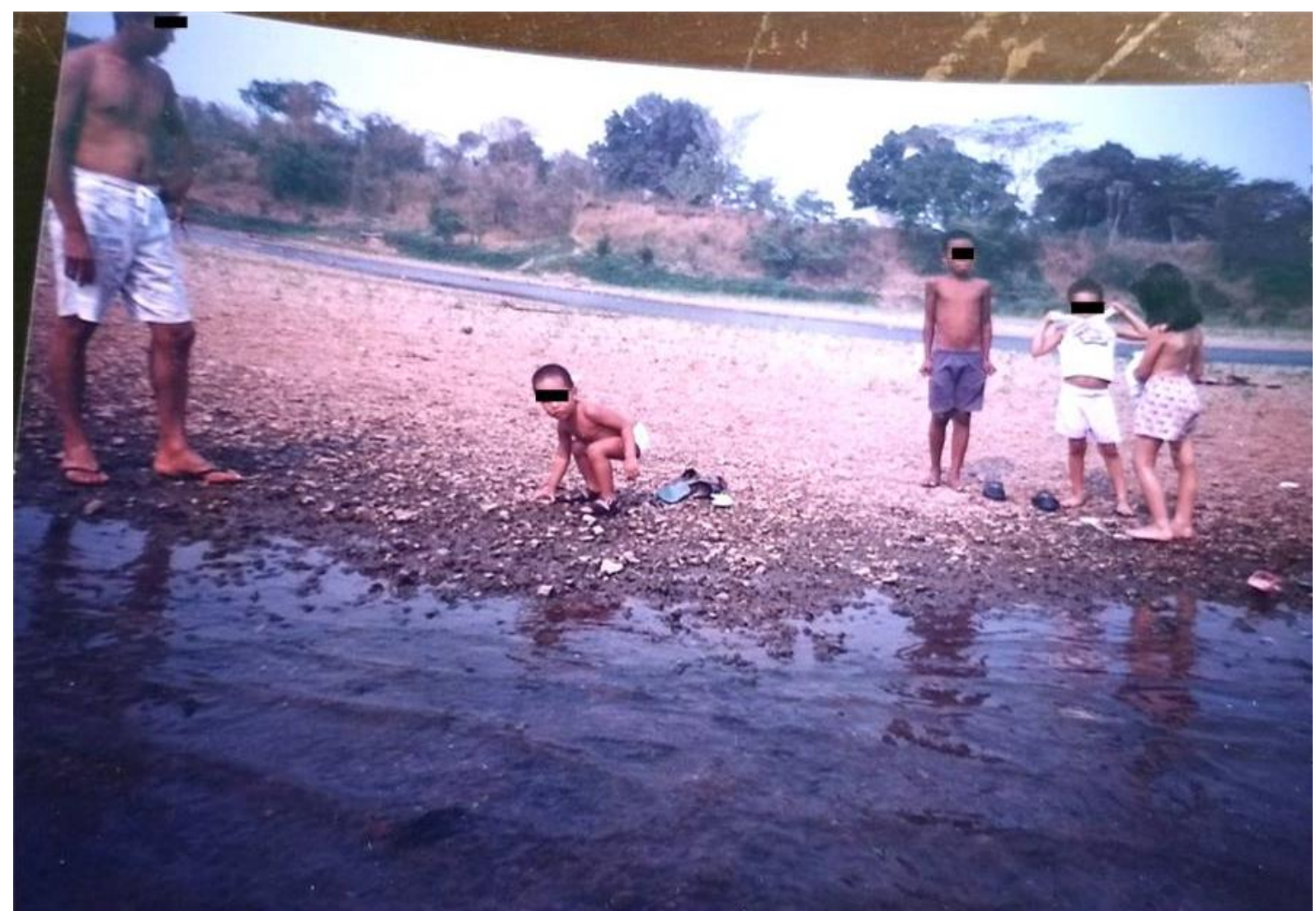

Figura 5: Visualização do uso recreativo das praias na década de 1990. Fonte: Acervo da Associação dos Moradores de São Gonçalo Beira Rio.

Em alguns casos, essas praias são localidades propícias aos roçados, que é um dos modelos de exercício da agricultura existente no lugar ribeirinho (Fig. 6). Almeida (2016, p. 6) afirma que em comunidades rurais é "onde se planta maior quantidade visando a uma produção equivalente ou superior ao cultivado, para fins às vezes comerciais ou de troca".

$\mathrm{O}$ roçado nas margens dos rios é uma atividade vista como tradicional em comunidades ribeirinhas (TOREZAM, 1986). Ele pode ser observado em diferentes trechos da bacia, no alto, médio e baixo curso, predominantemente no último. As espécies plantadas variadas podem ser: abóbora, mandioca, bananas e cana de açúcar, entre outros (Fig. 7) 


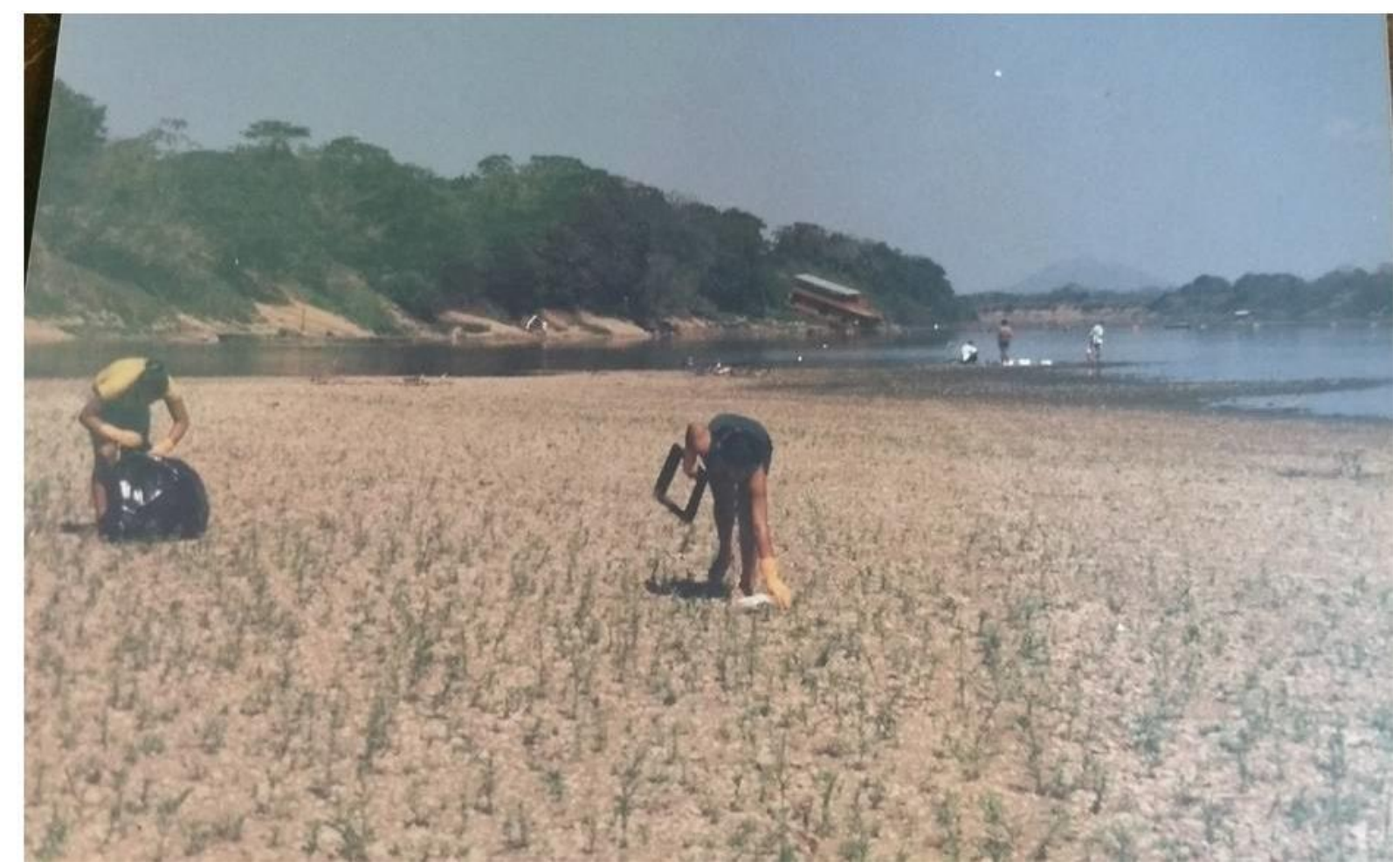

Figura 6: Preparação da praia para plantio do roçado, na década 1990. Fonte: Acervo da Associação dos Moradores de São Gonçalo Beira Rio. 

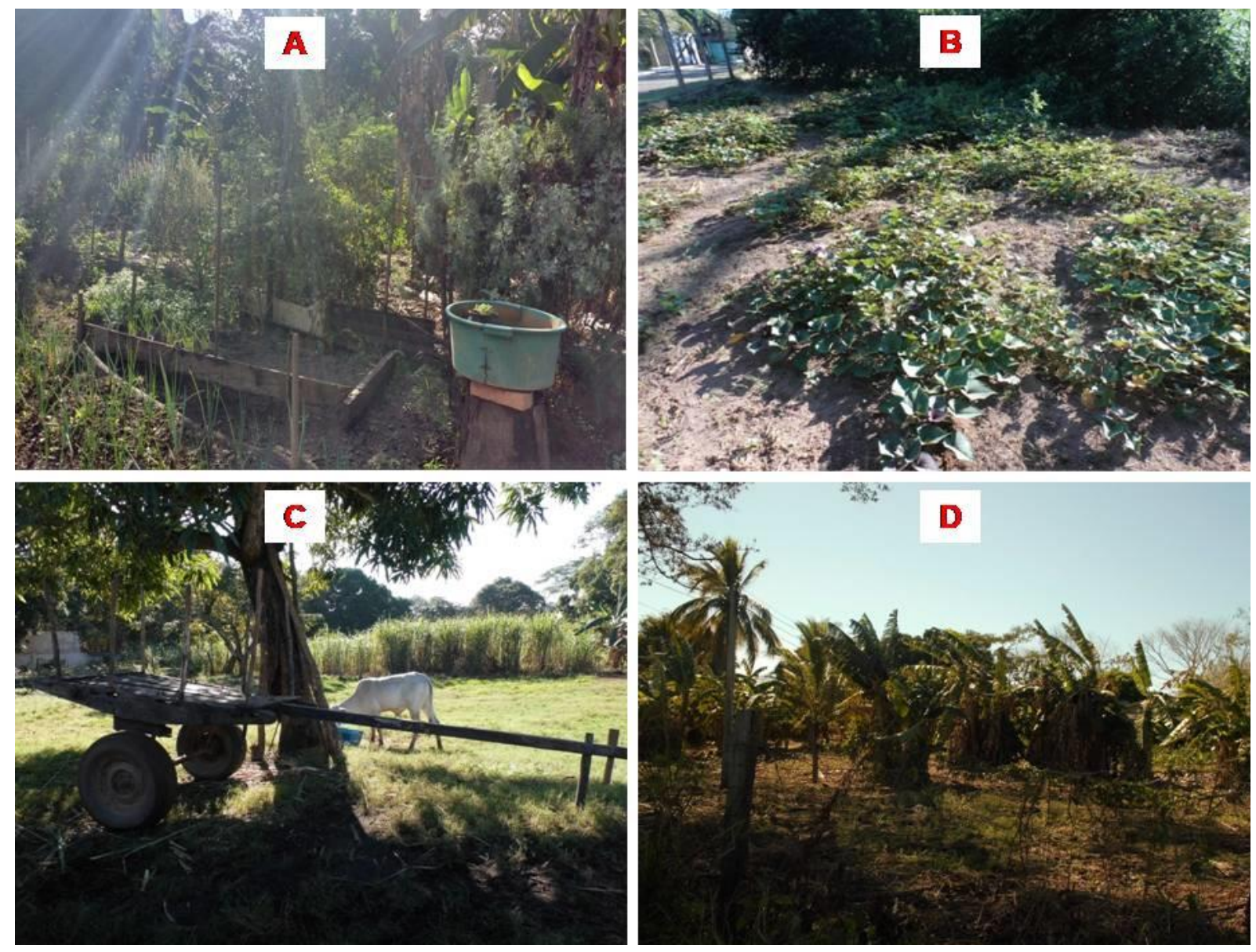

Figura 7: Mosaicos das áreas de roçados nas comunidades a margem do Rio Cuiabá. A Hortaliças e variedade medicinais; B - Batata doce; C- Cana de açúcar e gado para mover engenho, e D- Bananal.

Conforme Torezam (1986), esse tipo lavoura, até o século XVI, era a principal paisagem do Rio Cuiabá. Conforme a autora, a criação dos roçados foi uma imposição legal, visando garantir a subsistência da população que adentrou a localidade em busca do ouro. Dentre os principais gêneros alimentícios estavam o feijão, o milho e o arroz.

No tocante a produção dos roçados em comunidades ribeirinhas do Rio Cuiabá, Januário (1997) afirma que, até 1970, a maior parte das frutas, legumes e verduras consumidas pela população da capital era oriunda destas localidades. Todo processo de escoamento e comercialização era feito por meio do rio, nos portos.

Outro lugar no qual há a produção do território vivido dos ribeirinhos são as baias. Elas "são corpos d'águas que surgem devido à sazonalidade dos níveis de chuva e possuem ligamentos permanentes ou temporários com os rios do entorno chamados de corixos". Em suma, biologicamente falando, são ambientes aquáticos ligados e irrigados por um rio, neste caso, o Cuiabá (SOBRINHO e ALVES, 2011, p.255). 
A dinâmica natural envolta nessas baias está ligada a presença de uma formação geológica de serras graníticas, a Serra De São Vicente. Ela modela e impõe os limites a esses locais (Fig. 8). Assim, de acordo com Silveira e Da Silva (2000), as duas maiores e principais baias da região, Chacororé e Sinhá Mariana, formaram no passado, importantes espaços de assentamento humanos para os indígenas e negros escravizados. Em tempos atuais, uma delas, a Sinhá Mariana, abriga pousadas e pesqueiros para o atendimento das demandas do turismo de observação e de pesca.
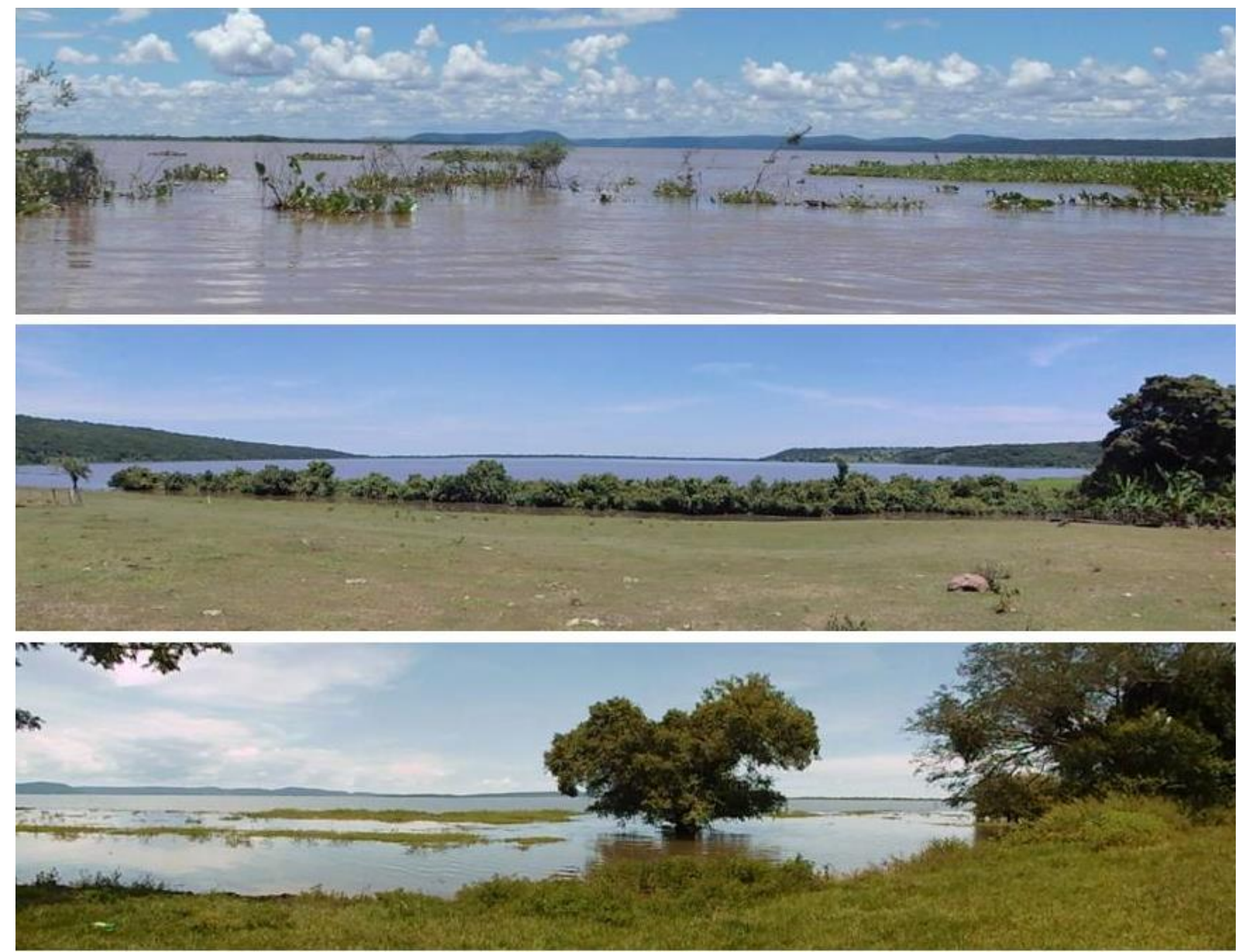

Figura 8: Visão de diferentes pontos da Baia de Chacororé, Barão de Melgaço - MT.

Sobre a relação dos ribeirinhos com as baias ela está diretamente ligada ao entendimento de que esse ecossistema é "berço dos peixes do pantanal”. Há entre esses homens e mulheres o acordo tácito de que nos meses reprodutivos dos animais a pesca nessas localidades é um desrespeito com o Pantanal. Para os sujeitos "o ribeirinho sabe que lá não deve pescar".

Esse saber é transmitido e reafirmado nas relações familiares, como no exemplo da senhora (A), de 55 anos, que, apesar de ter nascido no Pantanal, não conhece Sinhá Mariana e 
Chacororé. Ela nunca foi até as citadas localidades. No entanto, confidencia que ainda quando pequena ouvia os adultos falarem sobre a coloração escura da água, dos ventos fortes que viravam as canoas.

Para os ribeirinhos o encantamento das baias está em sua beleza singular, e por ser um arquivo vivo de seus próprios imaginários, os mesmos dizem: “[...] elas conservam estórias e mistérios". Elas guardam em si o simbolismo de sua construção como seres viventes do ambiente pantaneiro, que vivem, se adaptam e se moldam pela sinuosidade das águas de seus rios.

\section{Considerações finais}

As margens do Rio Cuiabá, mais precisamente as localidades que ajudam a compor Pantanal é habitada por homens e mulheres que denominamos ribeirinhos. Diferentes dos demais habitantes, a vida dessas pessoas, em alguns aspectos é guiada pelo envolvimento com o ambiente. Essa relação é portadora de metáforas que precisam ser desvendadas, como textos que foram inscritos no cotidiano.

Assim, é no anseio de decifrar as minúcias que, por ventura, possam responder um pouco mais sobre essas pessoas, escrevemos esse artigo. Sob aporte da Geografia Humanista Cultural, nos propusemos desvelar ainda de forma inicial, como eles dão sentido ao seu espaço.

A primeira menção que podemos elaborar efetivamente é que os ribeirinhos realizam a sua espacialidade por meio dos vínculos criado no lugar. Estes são originários na efetivação da pesca, no lazer, nas celebrações e culto aos ancestrais. Com isso territórios podemos designar um território que emerge a partir dos seus lugares. Isto é, o grande pântano comporta simbolicamente o que, via de regra, apreendemos como território vivido desses homens e mulheres.

Com base no que se observou, presumimos que o território dessas pessoas é anterior ao viés instrumental, pois independe das fronteiras empreendidas pelo Estado. Seu início e fim são criados e recriados na utilidade histórica, que fica evidente no cotidiano a partir da função de cada um dos lugares apresentados. 


\section{Referências bibliográficas}

ALMEIDA, M. G. Aportes teóricos e percursos epistemológicos da Geografia Cultural. GEONORDESTE, Ano XIX, n.1, p.35-54, 2008.

ALMEIDA, M. G. Comunidades tradicionais quilombolas do nordeste de Goiás: quintais como expressões territoriais. Revista Confins, n 29, 2016.

ALMEIDA, M. G. Geografia Cultural: contemporaneidade e flashback na sua ascensão no Brasil. In: MENDONÇA, F.; LOWEN-SAHR, C. L; SILVA, M. Espaço e Tempo: complexidade e desafios do pensar e do fazer geográfico. Curitiba: ANPEGE, ADEMADAN, 2009, p.243-260.

ALMEIDA, M.G. Territorialidades, representações do mundo vivido e modos de significar o mundo: Uma leitura etnogeográfica do Brasil sertanejo. In: SERPA, A. ( ORG). Espaços culturais: vivências, imaginações e representações.Salvador: EDUFBA, 2008.

BONNEMAISON, J. Viagem em torno do território. In: CORREA, R. L.; ROSENDAHL, Z. Geografia Cultural: um século. (3) Rio de Janeiro: Eduerj.2002.p.83-132.

BORGES, A. C. S. Nas margens da História: Meio ambiente e ruralidade em

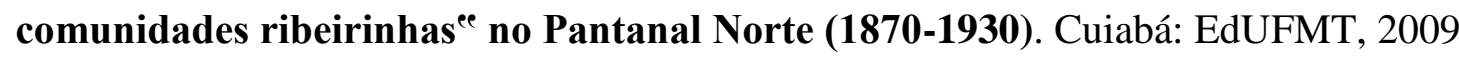

CARLOS, A. F. A. O lugar no/do mundo. FFLCH, 2007, 85p.

CHAVEIRO, E. F. Corporeidade e lugar: elos da produção da existência. In: MARANDOLA JR., E.; WERTHER, H.; OLIVEIRA, L.(Orgs.). Qual é o espaço do lugar? Geografia, epistemologia, fenomenologia. São Paulo: Perspectiva, 2012

CLAVAL, P. A Geografia Cultural. (Tradução de Luiz Fugazzola Pimenta e Margareth de Castro Afeche Pimenta.) 3 ${ }^{a}$ ed. Florianópolis: Ed. da UFSC, 2007.

DE PAULA, F. C. Sobre a dimensão vivida do território: tendências e contribuições da fenomenologia. Geotextos, vol.7, n.1, p.105-126, jul.2011.

FERREIRA, M. S. F. D. Lugar, Recursos e saberes dos ribeirinhos do médio rio Cuiabá, Mato Grosso. 2010. Tese (Doutorado em Ecologia e Recursos Naturais) - Pós-Graduação em Ecologia e Recursos Naturais, Universidade Federal de São Carlos, São Carlos, 2010.

FRAXE, T. Cultura cabocla-ribeirinha: mitos, lendas e transculturalidade. São Paulo: Annablume, 2004.

GOMES, P. C. Geografia e modernidade. 10 ed. Rio de Janeiro: Bertrand Brasil, 2011.

HAESBAERT, R. O mito da desterritorialização:fim dos territórios à multiterritorialidades. Rio de Janeiro: Bertrand Brasil, 2001.

HARTSHORNE, R. Perspectives on the Nature of Geography. Chicago: Rand Mc Nally. 1959

HOLZER, W. O lugar na Geografia Humanista. Revista Território, ano IV, n 7, p.67-78. Julho. Dezembro de 1999.

HOLZER, W. Uma discussão fenomenológica sobre os conceitos de paisagem, lugar, território e meio ambiente. Revista Território. Rio de Janeiro, ano II, n. 3, p. 77-85, jul./dez. 1997.

HOUAISS, A. Dicionário Houaiss da Língua Portuguesa. Rio de Janeiro, Ed. Objetiva, 2014. 
JANUÁRIO, E. R.S. As vidas do Ribeirinho: meio ambiente, cotidiano e educação na comunidade ribeirinha do São Gonçalo. Cuiabá: UFMT, 1997. Dissertação de Mestrado em Educação e Meio Ambiente, Instituto de Educação, Universidade Federal de Mato Grosso, 1997.

KOZEL, S. Um panorama sobre as geografias marginais no Brasil. In. HEIDRICH, Á. L.; COSTA, B. P.; PIRES, C. L. Z. (Orgs.). Maneiras de ler: geografia e cultura [recurso eletrônico] /. - Porto Alegre: Imprensa Livre: Compasso Lugar Cultura, 2013.

LITTLE, P. Territórios Sociais e Povos Tradicionais no Brasil: por uma antropologia da territorialidade. Brasília: Universidade de Brasília, Série Antropologia no 322, 2002.

OLIVEIRA, L. O sentido do Lugar. In: MARANDOLA JR., E.; WERTHER, H.; OLIVEIRA, L.(Orgs.). Qual o Espaço do Lugar? Geografia, Epistemologia, Fenomenologia. São Paulo: Perspectiva, 2014. p. 03-16.

RELPH, E. Reflexões Sobre a Emergência, Aspectos e Essência de Lugar. In: MARANDOLA JR., E.; WERTHER, H.; OLIVEIRA, L.(Orgs.). Qual o espaço do lugar?geografia, epistemologia, fenomenologia. São Paulo: Perspectiva, 2014, p. 17-32. RELPH, E. Place and Placelessness. London:Pion, 1976.

SILVA, A. G. S. Culturas desviantes:andanças amazônicas pelo Vale do Guaporé. Goiânia: Editora UFG, 2014.

SILVA, C. J. No ritmo das águas do pantanal. São Paulo: NUPAUB/USP, 1995.

SOBRINHO, J. A. F.;ALVES, M. . Variação temporal da assinatura espectral da baia de Chacororé no Pantanal de Mato Grosso. In: Anais XV Simpósio Brasileiro de Sensoriamento Remoto - SBSR, Curitiba, PR, Brasil, 30 de abril a 05 de maio de 2011, INPE p.5255 5255.

TOREZAN, A. P. D. São Gonçalo: uma análise das transformações nas formas de obtenção da subsistência da população ribeirinha. Cuiabá: UFMT, 2000. Especialização em Antropologia, Departamento de Antropologia, Universidade Federal de Mato Grosso, 2000.

TUAN, Y-F. Topofilia: Um Estudo da Percepção, Atitudes e Valores do Meio Ambiente. Tradução: Lívia de Oliveira. São Paulo/Rio de Janeiro: Difel, 1980.

TUAN, Y-F. Espaço e lugar: a perspectiva da experiência. Tradução: Lívia de Oliveira. São Paulo:Difel, 1983.

TUAN,Y-F. Geografia Humanística. In: CHRISTOFOLETTI, Antonio (Org). Perspectivas da Geografia. Rio Claro: Difel, 1995, p.144-164.

Recebido em 28 de agosto de 2018.

Aceito em 20 de setembro de 2018. 